\title{
High-Temperature Shape Memory Behavior of Semicrystalline Polyamide Thermosets
}

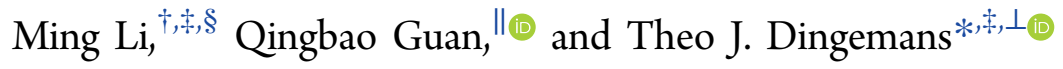 \\ ${ }^{\dagger}$ National Engineering Research Center for Biotechnology, Nanjing Tech University, Nanjing 211800, China \\ ${ }^{\ddagger}$ Faculty of Aerospace Engineering, Delft University of Technology, Kluyverweg 1, 2629 HS Delft, The Netherlands \\ ${ }^{\S}$ Dutch Polymer Institute (DPI), P.O. Box 902, 5600 AX Eindhoven, The Netherlands \\ "Department of Material Science and Engineering, Soochow University, Suzhou 215123, China \\ ${ }^{\perp}$ Department of Applied Physical Sciences, University of North Carolina at Chapel Hill, 1113 Murray Hall, Chapel Hill, North \\ Carolina 27599-3050, United States
}

\section{Supporting Information}

\begin{abstract}
We have explored semicrystalline poly(decamethylene terephthalamide) (PA 10T) based thermosets as single-component high-temperature $\left(>200{ }^{\circ} \mathrm{C}\right)$ shape memory polymers (SMPs). The PA $10 \mathrm{~T}$ thermosets were prepared from reactive thermoplastic precursors. Reactive phenylethynyl (PE) functionalities were either attached at the chain termini or placed as side groups along the polymer main chain. The shape fixation and recovery performance of the thermoset films were investigated using a rheometer in torsion mode. By controlling the $M_{n}$ of the reactive oligomers, or the $\mathrm{PE}$ concentration of the PE side-group functionalized copolyamides, we were able to design dual-shape memory PA 10T thermosets with a broad recovery temperature range of $227-285{ }^{\circ} \mathrm{C}$. The thermosets based on the $1000 \mathrm{~g} \mathrm{~mol}^{-1}$ reactive $\mathrm{PE}$ precursor and the copolyamide with $15 \mathrm{~mol} \% \mathrm{PE}$ side groups show the highest fixation rate (99\%) and recovery rate ( $\geq 90 \%)$. High temperature triple-shape memory behavior can be achieved as well when we use the melt transition $\left(T_{\mathrm{m}} \geq 200{ }^{\circ} \mathrm{C}\right)$ and the glass transition $\left(T_{\mathrm{g}}=\sim 125^{\circ} \mathrm{C}\right)$ as the two switches. The recovery rate of the two recovery steps are highly dependent on the crystallinity of the thermosets and vary within a wide range of $74 \%-139 \%$ and $40-82 \%$ for the two steps, respectively. Reversible shape memory events could also be demonstrated when we perform a forward and backward deformation in a triple shape memory cycle. We also studied the angular recovery velocity as a function of temperature, which provides a thermokinematic picture of the shape recovery process and helps to program for desired shape memory behavior.
\end{abstract}

KEYWORDS: semiaromatic polyamides, semicrystalline thermosets, high-temperature shape memory, dual-shape memory, triple-shape memory, recovery velocity

\section{INTRODUCTION}

Interest in shape memory polymers (SMPs) has grown rapidly since the 1980s. ${ }^{1-5}$ Typical applications are heat-shrink tubing, temperature sensors and actuators, biomedical and surgical materials, and aerospace devices. ${ }^{6,7}$ Thermoresponsive SMPs are the most investigated systems that polymers are able to adopt a temporary shape upon deformation and to revert back to the permanent shape upon exposure to heat. ${ }^{7,8}$ They are generally composed of a polymer network to maintain the permanent shape and a reversible switch responsible for the shape fixation and recovery. ${ }^{8-11}$ The glass transition temperature $\left(T_{\mathrm{g}}\right)$ and melting temperature $\left(T_{\mathrm{m}}\right)$ are the two most important thermal transitions for thermoresponsive SMPs. Polyurethanes, polyesters, and (methyl)acrylate-based polymer networks have been investigated as SMPs based on the glass transition. Cross-linked semicrystalline networks or (multi)block copolymer systems have been developed to design $T_{\mathrm{m}}$ based SMPs, such as polyolefins, polyethers, and polyesters. ${ }^{6}$
However, most SMPs exhibit a switching temperature lower than $100{ }^{\circ} \mathrm{C}$, which may not meet the requirements for high temperature aerospace, automotive, or electronic applications.

Recently, several examples of high-temperature $\left(>200{ }^{\circ} \mathrm{C}\right)$ SMPs have been reported. ${ }^{12-21}$ Vaia and co-workers synthesized an amorphous fluorinated polyimide with a shape recovery temperature of $220{ }^{\circ} \mathrm{C} .{ }^{20}$ This was the first example of a single-component high-temperature SMP. However, this fluorinated polyimide can only be obtained as thin films, which excludes the possibility to produce complex shapes using melt processing methods. Weiss et al. have introduced ionic moieties into poly(ether ether ketone) (PEEK) leading to a $T_{\mathrm{g}}$-based SMP with a switching temperature close to $200{ }^{\circ} \mathrm{C}$, where the exact switching temperature depends on the metal counterions

Received: March 4, 2018

Accepted: April 27, 2018

Published: May 9, 2018 


\section{Scheme 1. Structures of Precursors via (A) Reactive End-Group Approach and (B) Reactive Side-Group Approach}

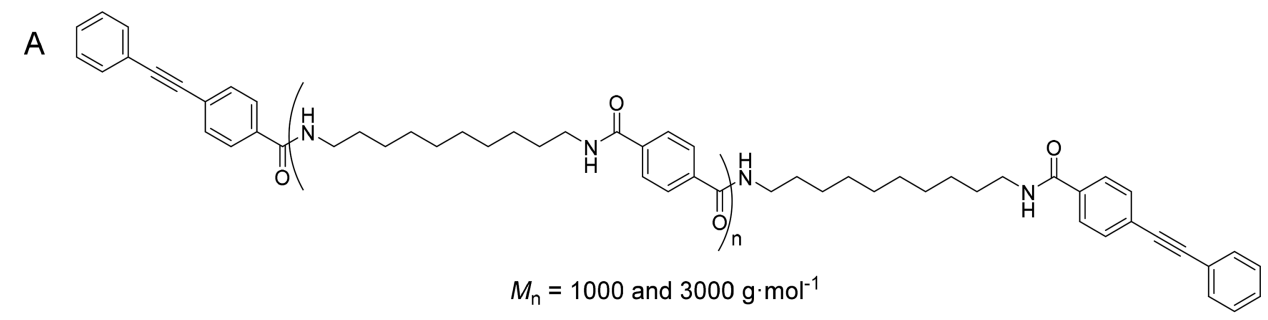

A. Reactive end-group approach

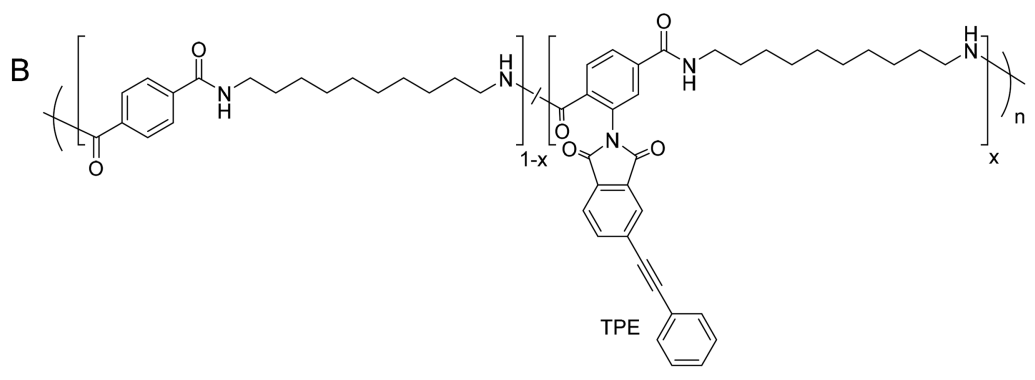

$\mathrm{x}=5,10$ and $15 \mathrm{~mol} \%$

B. Reactive side-group approach

used. ${ }^{14}$ In a later publication, this system was further developed into a $T_{\mathrm{m}}$-based SMP by incorporation of sodium oleate, which displays a higher switching temperature of $230-240{ }^{\circ} \mathrm{C}$ due to the melting of sodium oleate. ${ }^{15}$

In contrast to the dual SMPs mentioned above, triple SMPs featuring two independent temporary shapes were first reported by Lendlein's group. ${ }^{22}$ They require two programming steps and show two recovery steps. Triple-shape memory effects can be realized in a polymer material possessing two distinct thermal transitions ${ }^{15,22-24}$ or one single broad transition such as a broad glass transition. ${ }^{16,25}$ High temperature triple SMPs based on a single-component thermotropic liquid crystalline poly(esterimide) thermosets have recently been reported by Guan et al. The polymer shows two glass transition temperatures at $\sim 120$ and $\sim 200{ }^{\circ} \mathrm{C}$, both of which can be used as switches for triple SMPs. ${ }^{21}$

In previous publications we reported on the synthesis and (thermo)mechanical properties of semiaromatic polyamide thermosets based on poly(decamethylene terephthalamide) (PA 10T). ${ }^{26,27}$ We showed that this class of polymers can be processed into semicrystalline thermoset films where the degree of crystallinity can be controlled. The melting/crystallization of the crystalline phase and the covalent network can be used as the high-temperature switch and permanent scaffold, respectively, for a dual shape memory effect (SME). More sophisticated triple and one-way reversible SME can be designed with the glass transition as the second switch. To the best of our knowledge, this is the first demonstration of a high-temperature SMP based on a single-component semicrystalline polyamide thermoset.

\section{EXPERIMENTAL SECTION}

2.1. Materials. The syntheses of phenylethynyl (PE) end-capped PA 10T oligomers (Scheme 1A) and PE side-group-functionalized copolyamides (Scheme 1B) have been described in detail elsewhere. ${ }^{26,27}$ In order to obtain a covalently cross-linked polyamide network, the reactive precursors were thermally cured. A standard melt compression technique was used to prepare the thermoset films according to the following procedure: The precursor polymers were ground into a fine powder using a mortar and pestle. The powder was placed between two metal plates lined with Kapton film, and this stack was consolidated in a Joos hot-press using a predetermined temperature program and a $5 \mathrm{kN}$ force. The temperature program was set to heat to $350{ }^{\circ} \mathrm{C}$ at $5{ }^{\circ} \mathrm{C} \mathrm{min}{ }^{-1}$, hold for $15 \mathrm{~min}$, and cooled to $50{ }^{\circ} \mathrm{C}$ at $20{ }^{\circ} \mathrm{C} \mathrm{min}^{-1}$. The obtained cured films were used for further characterization.

The film samples prepared from PA 10T reactive oligomers $\left(M_{\mathrm{n}}\right.$ of 1000 and $3000 \mathrm{~g} \mathrm{~mol}^{-1}$ ) are denoted as PE-1K and PE-3K. TPE-5, TPE-10, and TPE-15 represent the film samples prepared from reactive TPE-copolyamides with 5,10 , and $15 \mathrm{~mol} \%$ of reactive TPE comonomer, respectively. A PA 10T thermoplastic sample $\left(M_{n}=7500\right.$ $\left.\mathrm{g} \mathrm{mol}^{-1}\right)$ was used as the reference in this paper and denoted as Ref. The ${ }^{1} \mathrm{H}$ NMR spectra of the synthesized precursors (Supporting Information, Figure S1) confirms that the concentration of reactive functionalities, either as end-caps or as side groups, is consistent with the feed ratio of the monomers.

2.2. Characterization. ${ }^{1} \mathrm{H}$ NMR spectra were recorded on a 400 $\mathrm{MHz}$ Bruker WM- 400 at $25{ }^{\circ} \mathrm{C}$ using trifluoroacetic acid- $d$ as solvent. DSC was conducted on a PerkinElmer Sapphire DSC under a nitrogen atmosphere at a heating/cooling rate of $20{ }^{\circ} \mathrm{C} \mathrm{min}^{-1}$. DMTA was performed on a PerkinElmer Diamond DMTA with film samples $\left(0.2-0.3 \mathrm{~mm}\right.$ thick) at a heating rate of $2{ }^{\circ} \mathrm{C} \mathrm{min}^{-1}$ under a nitrogen atmosphere. Data were collected at a frequency of $1 \mathrm{~Hz}$.

The SME was characterized in a cyclic torsion mode as illustrated in Figure 1. Compared to the traditional extension or bending tests, ${ }^{28}$ torsion tests involve nonhomogeneous strains and stresses in the cross section of a rectangular bar and enable the SMPs to reach large deformations with moderate strains, which are believed to be more representative of practical applications of SMPs. ${ }^{29-32}$

The shape programming and recovery cycles were performed using a Thermofisher Haake MARS III rheometer equipped with a solid clamp geometry under a $\mathrm{N}_{2}$ atmosphere. Rectangular thin films with a width of $\sim 2.5 \mathrm{~mm}$ and thickness of $\sim 0.25 \mathrm{~mm}$ were loaded into the setup with a length of $15 \mathrm{~mm}$ between the clamps. The samples were deformed in a torsion mode at a constant strain rate of $0.1 \% \mathrm{~s}^{-1}$ equivalent to a rotation speed of $3.4^{\circ} \mathrm{s}^{-1}$.

The procedure of one cycle for a dual SME test includes the following steps: (1) heat the sample to the programming temperature 


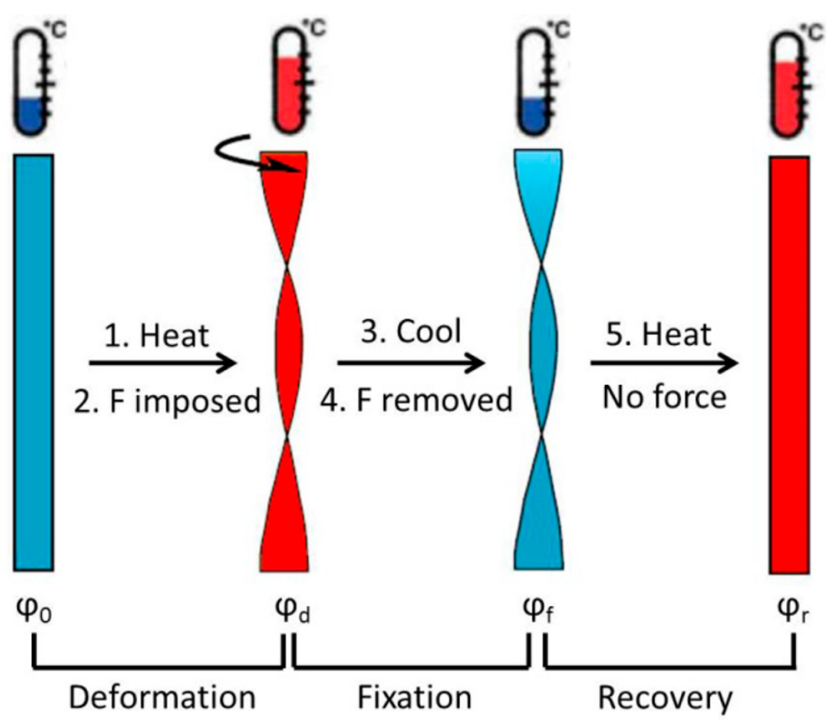

Figure 1. Illustration of a shape deformation, fixation, and recovery cycle of the dual SME in torsion mode.

$\left(T_{\text {prog }}\right) ;(2)$ rotate the sample to the predetermined angle $\left(\phi_{\mathrm{d}}\right) ;(3)$ keep the angle constant, cool to the fixation temperature $\left(T_{\mathrm{f}}\right)$ at $10{ }^{\circ} \mathrm{C}$ $\mathrm{min}^{-1}$ and stabilize for $10 \mathrm{~min}$; (4) remove the stress; (5) heat the sample to $T_{\text {prog }}$ at $10{ }^{\circ} \mathrm{C} \mathrm{min}-1$ in a stress-free condition followed by an isothermal hold at $T_{\text {prog }}$ for $10 \mathrm{~min}$ to stabilize. This cycle was repeated multiple times to characterize the reproducibility of the shape memory performance. The rotation angle of the sample was monitored and recorded during the whole test. For triple SME measurements, the sample was consecutively deformed in two steps in one programming cycle. Two different $T_{\text {prog }}$ s were used, one being above $T_{\mathrm{m}}$ and the other between $T_{\mathrm{g}}$ and $T_{\mathrm{m}}$.

\section{RESULTS AND DISCUSSION}

3.1. Melting and Thermomechanical Properties. In general, either the $T_{\mathrm{g}}$ or the $T_{\mathrm{m}}$ transition of a polymer can be applied to trigger a dual-shape memory event; however, to achieve high-temperature triple-shape memory behavior in a single-component polymer is challenging, as two high-temperature temporary networks with distinct rubbery plateaus are required. ${ }^{15,22-24}$ One solution to realize this type of structure is to introduce moderate cross-links into a high- $T_{\mathrm{g}}$ semicrystalline polymer. In our previous work, we have explored a semiaromatic polyamide, PA 10T $\left(T_{\mathrm{g}}=\sim 125^{\circ} \mathrm{C}, T_{\mathrm{m}}=\sim 315^{\circ} \mathrm{C}\right)$, as the base polymer to prepare semicrystalline polyamide thermosets. Phenylethynyl (PE) shows high cure-temperature of $330-370^{\circ} \mathrm{C}$ and thus is able to provide a proper processing window for the PA 10T-based precursors. Therefore, we have synthesized a reactive PE-based end-cap and a reactive PEbased comonomer, which were copolymerized with terephthalic acid and 1,10-diaminodecane to yield curable PE end-capped oligomers and PE side-group functionalized copolymers. The polyamide thermosets were obtained after a subsequent thermal cure at a temperature of $350{ }^{\circ} \mathrm{C}$ for $15 \mathrm{~min}$. PE-1K and PE-3K refer to the cured end-capped oligomers with $M_{\mathrm{n}}=$ 1000 and $3000 \mathrm{~g} \mathrm{~mol}^{-1}$, respectively. TPE-5, TPE-10, and TPE15 represent the cured side-group functionalized copolyamides with 5, 10, and $15 \mathrm{~mol} \% \mathrm{PE}$ side groups, respectively.

The melting curves and properties of a thermoplastic PA 10T reference polymer (Ref) and the resultant polyamide thermosets are shown in Figure 2 and Table 1. The thermoset samples after cure are semicrystalline showing a $T_{\mathrm{m}}$ of $227-288$
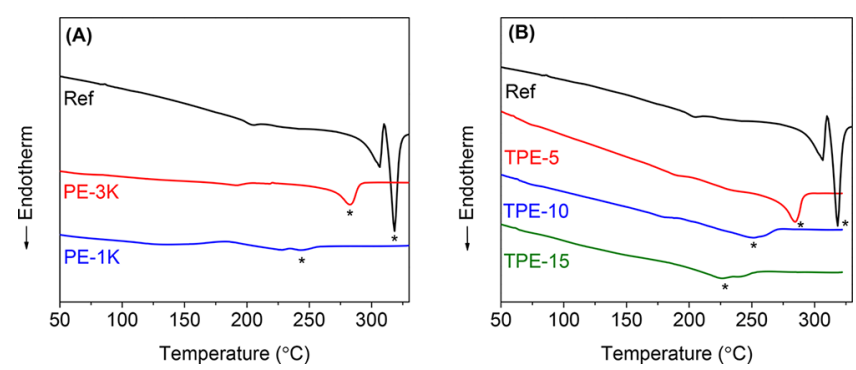

Figure 2. DSC heating scans (first heat) of (A) reference polymer (Ref), PE-3K, and PE-1K and (B) reference polymer (Ref), TPE-5, TPE-10, and TPE-15. The asterisk refers to melting peaks $\left(\mathrm{N}_{2}\right.$ atmosphere and heating rate of $20^{\circ} \mathrm{C} \mathrm{min}^{-1}$ ).

Table 1. Thermal Properties of the Thermoplastic Reference Polymer (Ref) and the Cured Thermoset Samples

$\begin{array}{lcccc}\text { sample } & \begin{array}{c}T_{\mathrm{m}}{ }^{a} \\ \left({ }^{\circ} \mathrm{C}\right)\end{array} & \begin{array}{c}\Delta H_{\mathrm{m}} \\ \left(\mathrm{J} \mathrm{g}^{-1}\right)\end{array} & \begin{array}{c}T_{\mathrm{g}}{ }^{b} \\ \left({ }^{\circ} \mathrm{C}\right)\end{array} & \begin{array}{c}\text { cross-linking density } \\ \left(\mathrm{kmol} \mathrm{m}^{c}\right)\end{array} \\ \text { Ref } & 318 & 82 & 127 & \\ \text { PE-3K } & 283 & 33 & 127 & 0.68 \\ \text { PE-1K } & 244 & 8 & 129 & 0.72 \\ \text { TPE-5 } & 285 & 33 & 123 & 0.94 \\ \text { TPE-10 } & 250 & 27 & 123 & 1.79 \\ \text { TPE-15 } & 227 & 20 & 125 & 2.34\end{array}$

${ }^{a} T_{\mathrm{m}}$ refers to the max of the melting peak as observed in DSC experiments. ${ }^{b} T_{\mathrm{g}}$ refers to the max of $E^{\prime \prime}$ as observed in DMTA experiments. ${ }^{c}$ Cross-linking density $(v)$ was calculated using $v=\frac{E^{\prime}}{3 R T}$, where $E^{\prime}$ is the storage modulus of cured films at $350^{\circ} \mathrm{C}(T=623 \mathrm{~K})$ and $R$ the universal gas constant $\left(8.314 \mathrm{~J} \mathrm{~K}^{-1} \mathrm{~mol}^{-1}\right)$.

${ }^{\circ} \mathrm{C}$ and $\Delta H_{\mathrm{m}}$ of $8-33 \mathrm{~J} \mathrm{~g}^{-1}$. These values are much lower than the $T_{\mathrm{m}}$ and the $\Delta H_{\mathrm{m}}$ of the reference polymer (Ref) $\left(318{ }^{\circ} \mathrm{C}\right.$ and $\left.82 \mathrm{~J} \mathrm{~g}^{-1}\right)$, which means the crystallizability of the polymer chains in the thermosets is strongly suppressed.

Figure 3 shows the thermomechanical behavior of the reference polymer (Ref) and the thermosets. The Ref film exhibits a $T_{\mathrm{g}}$ at $127^{\circ} \mathrm{C}$, but this film fails at $297^{\circ} \mathrm{C}$ because it has reached the melting point $\left(T_{\mathrm{m}}\right)$. In contrast to the reference polymer (Ref), the thermoset samples show two plateau regions $\left(T_{\mathrm{g}}-T_{\mathrm{m}}\right.$ and $\left.>T_{\mathrm{m}}\right)$ in the DMTA profiles. The second plateau of the thermosets is stable up to $\sim 400{ }^{\circ} \mathrm{C}$, which confirms the presence of a network structure. The $T_{\mathrm{g}} \mathrm{s}$ of both thermoset samples remain virtually unchanged $\left(123-129^{\circ} \mathrm{C}\right)$ when compared to that of the reference polymer (Ref).

The molecular structure of the resultant semicrystalline thermosets is depicted in Figure 4. PE groups combine at the cure temperature resulting in cross-links with multiple aftercure chemical structures depending on cure temperature, time, and PE concentration. We attempted to investigate the cure chemistry using Raman and FTIR spectroscopy ${ }^{33,34}$ However, Raman spectroscopy failed due to a strong fluorescence background, and FTIR cannot detect the acetylene bond of PE because of IR insensitivity. Hence, direct evidence is not available to confirm the chemical change of the PE functionalities. The DMTA results of the cured samples show a rubbery plateau above $T_{\mathrm{m}}$, and this plateau is stable up to $\sim 400{ }^{\circ} \mathrm{C}$, which confirms that cross-linking has taken place during cure. The two-plateau thermal behavior enables tripleshape memory properties by taking both $T_{\mathrm{g}}$ and $T_{\mathrm{m}}$ transitions as the switches. The $T_{\mathrm{m}}$ transition can be solely used as a switch 

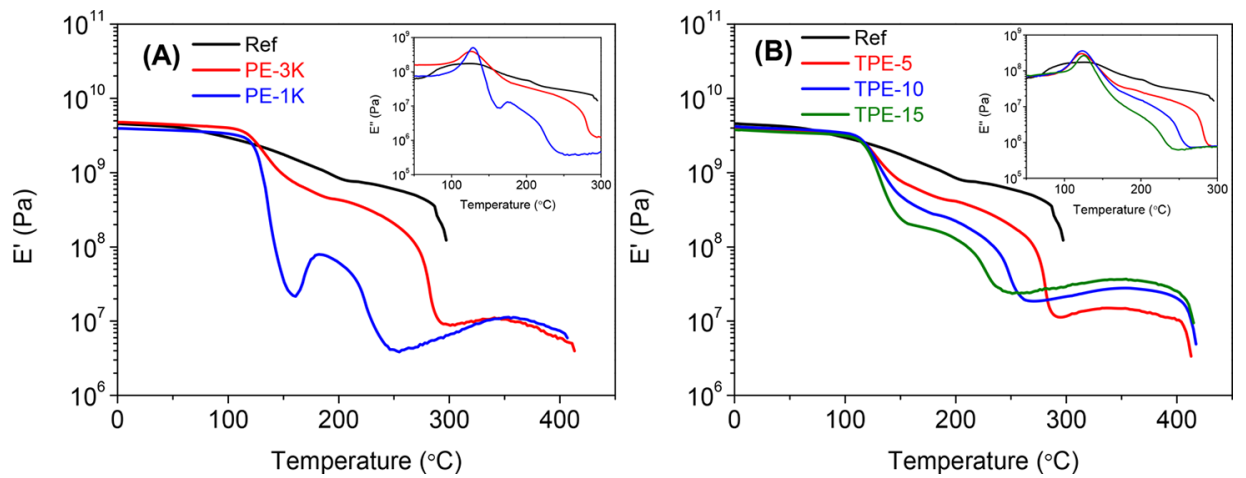

Figure 3. DMTA of (A) reference polymer (Ref), PE-1K, and PE-3K films and (B) reference polymer (Ref), TPE-5, TPE-10, and TPE-15 films. Heating rate $2{ }^{\circ} \mathrm{C} \mathrm{min}{ }^{-1}$ under $\mathrm{N}_{2}$ atmosphere and a frequency of $1 \mathrm{~Hz}$. The insets show $E^{\prime \prime}$ at the glass transition temperature.

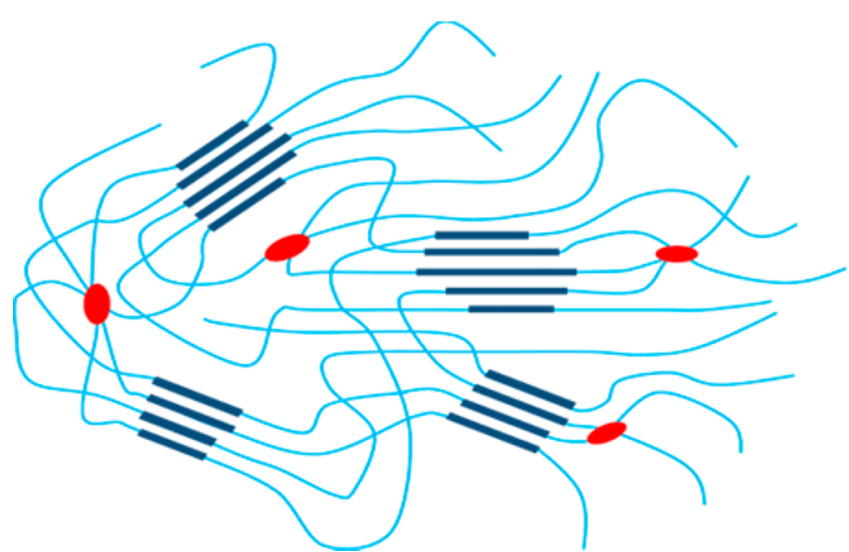

Figure 4. Molecular representation of the semicrystalline PA 10T thermosets. Crystalline polymer (dark blue) is embedded in an amorphous matrix (light blue), and the red dots represent covalent cross-link points.

to design a high-temperature $\left(>200{ }^{\circ} \mathrm{C}\right)$ dual-shape memory polymer.
3.2. Dual-Shape Memory Behavior. Because of the semicrystalline nature of the synthesized polyamide thermosets, their melting and crystallization processes can be used as the thermoresponsive switch for dual-shape memory behavior. Three consecutive deformation, fixation, and recovery cycles in a torsion mode were conducted for each sample to test the shape memory performance over multiple cycles.

Shape fixation rate $\left(R_{\mathrm{f}}\right)$ and shape recovery rate $\left(R_{\mathrm{r}}\right)$ are the most important parameters to characterize the shape memory performance. $^{35} R_{\mathrm{f}}$ describes how accurately the temporary shape can be fixed, and $R_{\mathrm{r}}$ quantifies the ability of the polymer to memorize its permanent shape. When performing the measurements in torsion mode, $R_{\mathrm{f}}$ and $R_{\mathrm{r}}$ can be calculated using eqs 1 and 2 .

$$
\begin{aligned}
& R_{\mathrm{f}}=\frac{\varphi_{\mathrm{f}}}{\varphi_{\mathrm{d}}} \times 100 \% \\
& R_{\mathrm{r}}=\frac{\varphi_{\mathrm{d}}-\varphi_{\mathrm{r}}}{\varphi_{\mathrm{d}}} \times 100 \%
\end{aligned}
$$

where $\varphi_{\mathrm{d}}, \varphi_{\mathrm{f}}$, and $\varphi_{\mathrm{r}}$ denote the rotational angle after deformation, at the fixed temporary shape at $T_{\mathrm{f}}$, and after
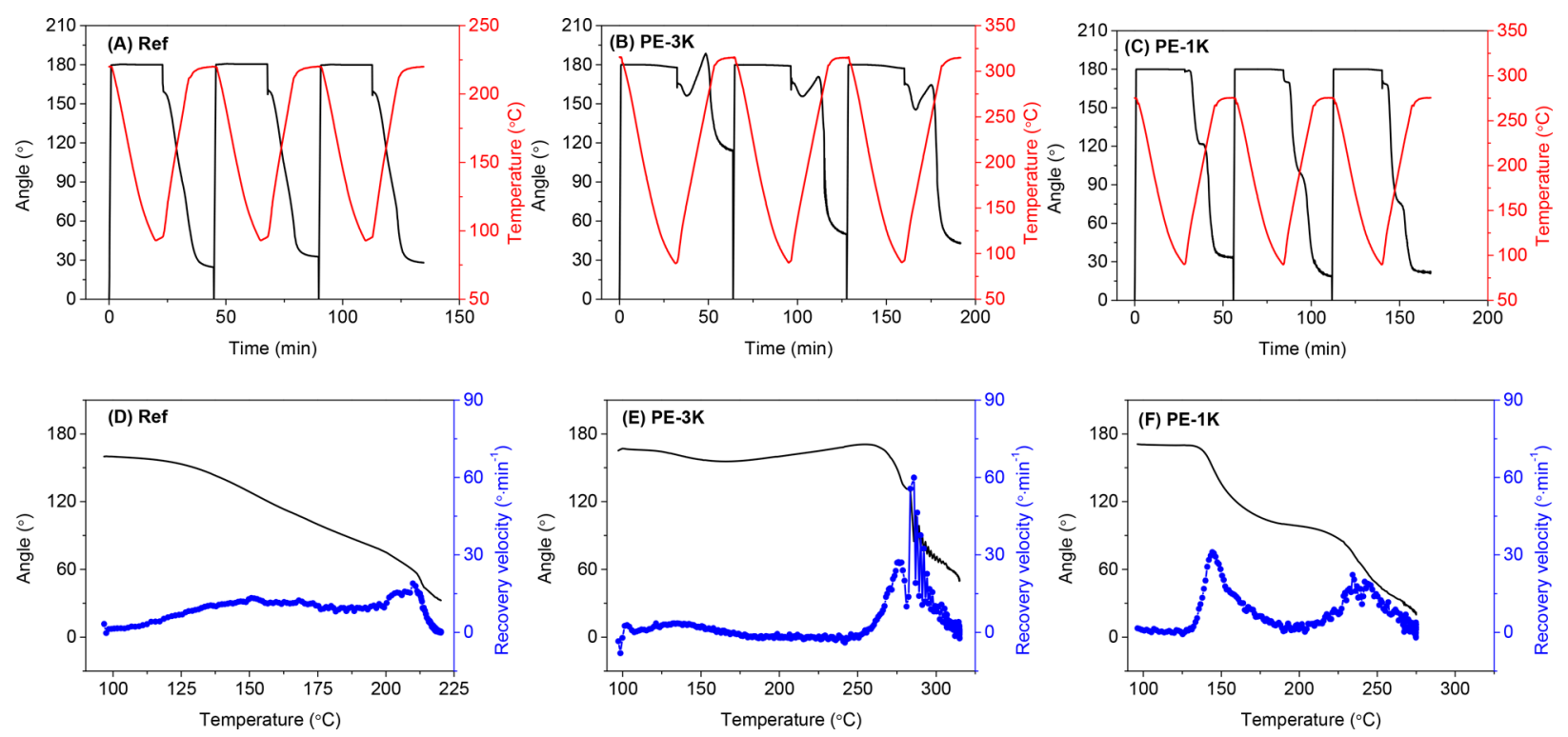

Figure 5. Three consecutive dual-shape memory cycles for (A) reference polymer (Ref), (B) PE-3K, and (C) PE-1K. Shape recovery velocity as a function of temperature in the second cycle for (D) reference polymer (Ref), (E) PE-3K, and (F) PE-1K. Cooling $/$ heating rate $10^{\circ} \mathrm{C}$ min ${ }^{-1}$ and $\mathrm{N}_{2}$ atmosphere. 
recovery, respectively. The instantaneous recovery velocity $V_{\mathrm{r}}$ can be calculated as the time derivative of the angle as shown in eq 3.

$$
V_{\mathrm{r}}=\frac{\partial \varphi}{\partial t}
$$

Plotting $V_{\mathrm{r}}$ against temperature reveals the temperature range corresponding to the shape recovery process. ${ }^{21}$ This provides a clear thermokinematic view of the shape recovery and helps to program for desired SME.

The thermoplastic reference film (ref) cannot be deformed above the melting temperature because of the absence of a rubbery plateau, thus the glass transition was used as the switch for the SME. As shown in Figure 5A, the sample was deformed at $220{ }^{\circ} \mathrm{C}$, which lies between $T_{\mathrm{g}}\left(127^{\circ} \mathrm{C}\right)$ and $T_{\mathrm{m}}\left(318^{\circ} \mathrm{C}\right)$, and the shape was fixed at $100{ }^{\circ} \mathrm{C}$ where the sample is in a glassy state. Therefore, the crystalline domains act as the scaffold, and the deformation of the polymer takes place in the amorphous state.

In contrast to the reference polymer (Ref), PE-3K and PE$1 \mathrm{~K}$ thermoset films are stable up to $\sim 400{ }^{\circ} \mathrm{C}$ in DMTA experiments and exhibit two plateau regions $\left(T_{\mathrm{g}}-T_{\mathrm{m}}\right.$ and $\left.>T_{\mathrm{m}}\right)$, as shown in Figure 3. This allows for deforming the film samples in the second plateau region $\left(>T_{\mathrm{m}}\right)$. Figures $5 \mathrm{~B}$ and $5 \mathrm{C}$ show that PE-3K and PE- $1 \mathrm{~K}$ were deformed at 315 and $275^{\circ} \mathrm{C}$, respectively, which is about $30{ }^{\circ} \mathrm{C}$ higher than their $T_{\mathrm{m}} \mathrm{s}(283$ and $\left.244{ }^{\circ} \mathrm{C}\right)$. At this temperature the covalent network acts as the scaffold, and the temporary shape is fixed by crystallization and vitrification at the fixation step. At the recovery step, the angle shows a slight decrease when the sample passes through the glass transition, which is associated with the release of the stress trapped in the mobile amorphous region. A subsequent slow increase in the angle is observed, which can be explained by thermal expansion. ${ }^{36}$ When the sample starts melting, the angle recovers rapidly due to the fast release of the trapped stress.

The shape-memory performance of the first few cycles is usually not representative, as can be seen in Figure 5B,C. This is generally attributed to residual strain from the processing history of the sample. ${ }^{13,35}$ Table 2 shows the fixation and

Table 2. Dual-Shape Fixation and Recovery Results of the Reference Thermoplastic Polymer (Ref), PE-3K, and PE-1K Thermoset Films

\begin{tabular}{|c|c|c|c|c|c|c|c|c|}
\hline \multirow[b]{2}{*}{ sample } & \multirow[b]{2}{*}{$\left.T_{\text {prog }}^{a}{ }^{b} \mathrm{C}\right)$} & \multirow[b]{2}{*}{$\begin{array}{c}T_{\mathrm{r}}^{b} \\
\left({ }^{\circ} \mathrm{C}\right)\end{array}$} & \multicolumn{2}{|c|}{ cycle 1} & \multicolumn{2}{|c|}{ cycle 2} & \multicolumn{2}{|c|}{ cycle 3} \\
\hline & & & $\begin{array}{c}R_{\mathrm{f}} \\
(\%)\end{array}$ & $\begin{array}{c}R_{\mathrm{r}} \\
(\%)\end{array}$ & $\begin{array}{c}R_{\mathrm{f}} \\
(\%)\end{array}$ & $\begin{array}{c}R_{\mathrm{r}} \\
(\%)\end{array}$ & $\begin{array}{c}R_{\mathrm{f}} \\
(\%)\end{array}$ & $\begin{array}{c}R_{\mathrm{r}} \\
(\%)\end{array}$ \\
\hline Ref & 220 & 210 & 89 & 86 & 89 & 82 & 89 & 84 \\
\hline PE-3K & 315 & 285 & 93 & 36 & 94 & 72 & 94 & 76 \\
\hline PE-1K & 275 & $\begin{array}{c}144 \\
240\end{array}$ & 99 & 81 & 98 & 90 & 95 & 88 \\
\hline
\end{tabular}

${ }^{a} T_{\text {prog }}$ refers to the programming temperature. ${ }^{b} T_{\mathrm{r}}$ refers to the temperature at the maximum recovery velocity.

recovery results of the first three cycles of the reference thermoplastic polymer (Ref), the PE-3K, and PE- $1 \mathrm{~K}$ thermoset films. The PE-3K film shows a very low $R_{\mathrm{r}}$ of $36 \%$ in the first cycle compared to the following cycles $\left(R_{\mathrm{r}}=72 \%\right.$ and $\left.76 \%\right)$, whereas the $R_{\mathrm{r}}$ of the PE-1K film shows a medium change over cycles $\left(R_{\mathrm{r}}=81 \%, 90 \%\right.$, and $\left.88 \%\right)$. Such significant difference can originate from the different cross-linking densities of these two samples. PE-3K has a lower cross-linking density and therefore longer polymer chains between cross-links, which is more likely to store residual strain. The recovery of both samples cannot reach $100 \%$ because the irreversible chainsegment orientation and the relaxation effect in the polymer network partly dissipate the stored entropy. ${ }^{20}$

The shape recovery velocity of the second cycle is plotted as a function of temperature as shown in Figure 5D-F. The reference polymer (Ref) shows a low velocity $\left(<20^{\circ} \mathrm{min}^{-1}\right)$ through the recovery process because the shape recovery is triggered by the activation of the amorphous chain segments, which are strongly restricted by the crystalline domains. A low recovery velocity is generally observed in $T_{\mathrm{g}}$-based shapememory polymers. ${ }^{8}$ In contrast, $\mathrm{PE}-3 \mathrm{~K}$ shows a quick recovery in the temperature range of $260-310{ }^{\circ} \mathrm{C}$ and reaches a maximum $V_{\mathrm{r}}$ of $\sim 60^{\circ} \mathrm{min}^{-1}$ at $285^{\circ} \mathrm{C}$, which is close to its $T_{\mathrm{m}}$ $\left(283{ }^{\circ} \mathrm{C}\right)$. The shape recovery is triggered by melting of the crystalline domains, which is a relatively fast process.

It is worthy to note that the PE- $1 \mathrm{~K}$ film was deformed at 275 ${ }^{\circ} \mathrm{C}$ in one step; however, this polymer shows two distinct recovery steps with a maximum recovery velocity of $20-30^{\circ}$ $\mathrm{min}^{-1}$ at around 144 and $240{ }^{\circ} \mathrm{C}$, respectively. The first recovery takes place when the sample passes through the glass transition and reaches an $R_{\mathrm{r}}$ of $\sim 42 \%$ at $200{ }^{\circ} \mathrm{C}$. The second recovery is triggered by the melting of the crystalline domains. These two recovery steps indicate that the crystalline domains in PE- $1 \mathrm{~K}$ are not able to form a penetrating scaffold throughout the sample and thus cannot completely lock the amorphous chains. This allows the sample to partially recover at the $T_{\mathrm{g}}-$ $T_{\mathrm{m}}$ range. These results demonstrate that the degree of crystallinity, which is reflected in the $\Delta H_{\mathrm{m}}$ values in Table 1 , strongly affects the shape memory behavior of our semicrystalline PAs.

The dual-shape memory behavior of the TPE-based thermosets were investigated using the same method. Table 3

Table 3. Dual-Shape Fixation and Recovery Results of the TPE Thermoset Films

\begin{tabular}{|c|c|c|c|c|c|c|c|c|}
\hline \multirow[b]{2}{*}{ sample } & \multirow[b]{2}{*}{$\begin{array}{c}T_{\text {prog }}^{a} \\
\left({ }^{\circ} \mathrm{C}\right)\end{array}$} & \multirow[b]{2}{*}{$\begin{array}{c}T_{\mathrm{r}}^{b} \\
\left({ }^{\circ} \mathrm{C}\right)\end{array}$} & \multicolumn{2}{|c|}{ cycle 1} & \multicolumn{2}{|c|}{ cycle 2} & \multicolumn{2}{|c|}{ cycle 3} \\
\hline & & & $\begin{array}{c}R_{\mathrm{f}} \\
(\%)\end{array}$ & $\begin{array}{c}R_{\mathrm{r}} \\
(\%)\end{array}$ & $\begin{array}{c}R_{\mathrm{f}} \\
(\%)\end{array}$ & $\begin{array}{c}R_{\mathrm{r}} \\
(\%)\end{array}$ & $\begin{array}{c}R_{\mathrm{f}} \\
(\%)\end{array}$ & $\begin{array}{c}R_{\mathrm{r}} \\
(\%)\end{array}$ \\
\hline TPE-5 & 315 & 277 & 93 & 62 & 93 & 82 & 94 & 82 \\
\hline TPE-10 & 295 & 242 & 98 & 66 & 96 & 78 & 96 & 79 \\
\hline TPE-15 & 275 & $\begin{array}{c}140, \\
227\end{array}$ & 99 & 93 & 99 & 93 & 97 & 96 \\
\hline
\end{tabular}

${ }^{a} T_{\text {prog }}$ refers to the programming temperature. ${ }^{b} T_{\mathrm{r}}$ refers to the temperature at the maximum recovery velocity.

shows the shape fixation and recovery results for these samples. All samples reveal good shape fixation with $R_{\mathrm{f}}$ values of 9399\%. The TPE-15 samples with the highest cross-linking density shown in Table 1 exhibit excellent recovery efficiency $\left(R_{\mathrm{r}}>90 \%\right)$, whereas the other samples show $R_{\mathrm{r}}$ values of $62-$ $66 \%$ in the first cycle and $78-82 \%$ in the second and third cycles.

Figure 6 shows the dual-shape memory cycles and the recovery velocity of the TPE thermoset films. Similar to the PE$3 \mathrm{~K}$ sample, TPE-5 and TPE-10 exhibit one recovery step in the temperature ranges of $260-300$ and $230-270{ }^{\circ} \mathrm{C}$, respectively. Interestingly, the TPE-15 film also displays two recovery steps, which is similar to that of the PE- $1 \mathrm{~K}$ film. The two recovery steps originate from the low degree of crystallinity in TPE-15 and PE-1K, where the amorphous chain segments cannot be 

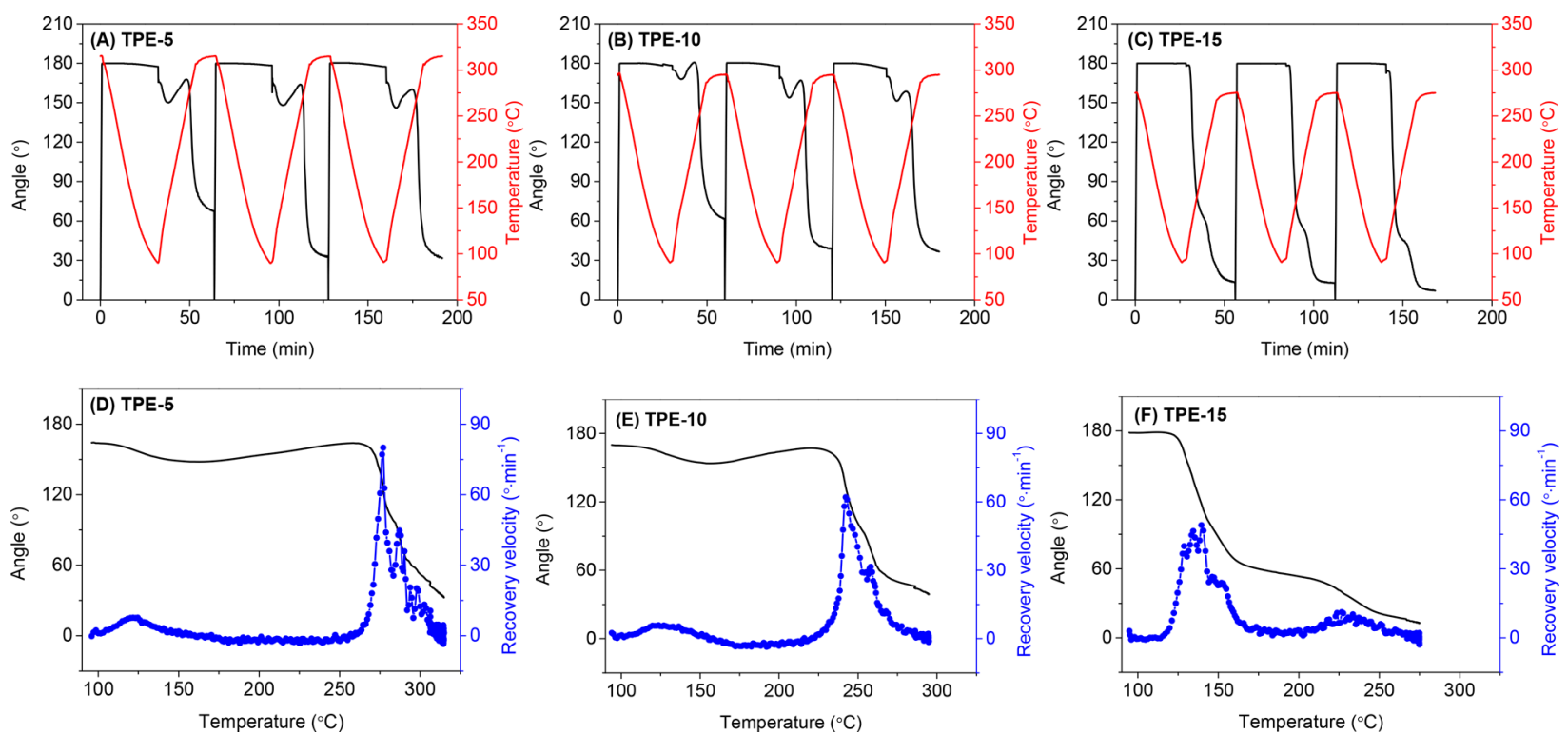

Figure 6. Three consecutive dual-shape memory cycles for the TPE series (A) TPE-5, (B) TPE-10, and (C) TPE-15. Shape recovery velocity as a function of temperature in the second cycle for the TPE series (D) TPE-5, (E) TPE-10, and (F) TPE-15. Cooling and heating rate $10^{\circ} \mathrm{C}$ min ${ }^{-1}$ and $\mathrm{N}_{2}$ atmosphere.
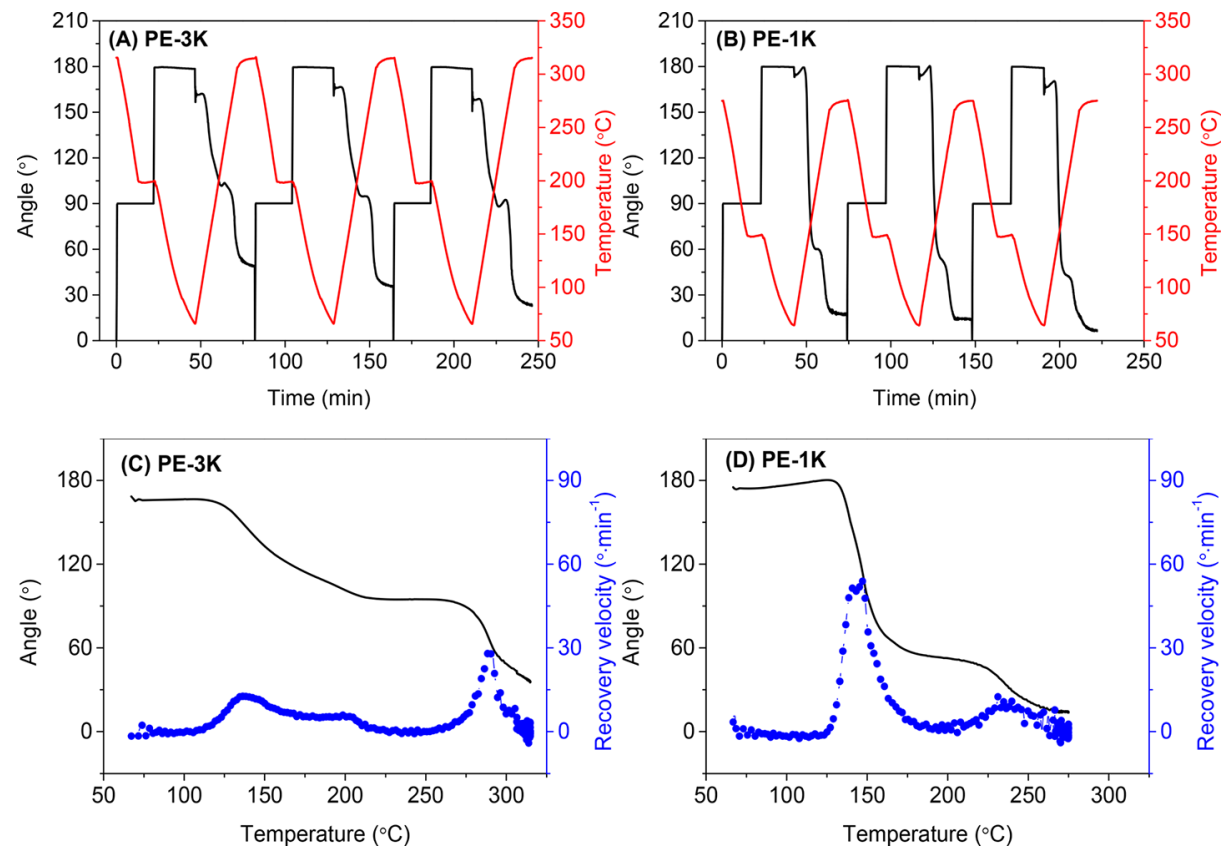

Figure 7. Three consecutive triple-shape memory cycles for the PE series (A) PE-3K and (B) PE-1K. Shape recovery velocity as a function of temperature in the second cycle for the PE series (C) PE-3K and (D) PE-1K. Cooling and heating rate $10^{\circ} \mathrm{C} \min ^{-1}$ and $\mathrm{N}_{2}$ atmosphere.

completely fixed when the temperature is above $T_{\mathrm{g}}$. TPE-5, TPE-10, and PE-3K, on the other hand, show higher degrees of crystallinity, and this prevents the $T_{\mathrm{g}}$-induced shape recovery.

The difference between these samples clearly indicates that the shape memory behavior strongly depends on the degree of crystallinity of the semicrystalline thermosets. By changing the concentration of the $\mathrm{PE}$ side groups in the reactive copolyamides, the cross-linking density of the thermosets can be controlled, consequently leading to adjustable crystallinity and shape memory behavior.

3.3. Triple-Shape Memory Behavior. Based on our study above, two reversible processes, the glass transition and the melting process, can both act as the switches to trigger shape recovery. Unlike the traditional high-temperature triple-SMP composed of multiple components, we were able to design a single-component triple-SMP using both switches to achieve two distinct recovery processes.

Figure 7A shows the three consecutive triple-shape memory cycles for PE-3K. The film sample was first heated up to 315 ${ }^{\circ} \mathrm{C}$, which is above the $T_{\mathrm{m}}\left(283^{\circ} \mathrm{C}\right)$ and rotated by $90^{\circ}$ from the original shape $\mathrm{A}\left(\varphi_{\mathrm{A}}\right)$ to a temporary shape $\mathrm{B}\left(\varphi_{\mathrm{B}}\right)$. The sample was cooled to $200{ }^{\circ} \mathrm{C}$, a temperature between $T_{\mathrm{m}}$ and $T_{\mathrm{g}}$, to fix the shape B. A second rotation of $90^{\circ}$ was then applied to reach the temporary shape $\mathrm{C}\left(\varphi_{\mathrm{C}}\right)$. The sample was subsequently cooled to $60{ }^{\circ} \mathrm{C}$, which is below the $T_{\mathrm{g}}$ of $127^{\circ} \mathrm{C}$, to fix the shape $\mathrm{C}$. The external stress was then removed, 
Table 4. Triple-Shape Fixation and Recovery Results of the PE- and TPE-Series Thermoset Films

\begin{tabular}{|c|c|c|c|c|c|c|c|c|c|c|c|c|c|}
\hline \multirow[b]{2}{*}{ sample } & \multirow[b]{2}{*}{$T_{\text {prog1 }}^{a}$} & \multirow[b]{2}{*}{$T_{\left.{ }_{\text {prog2 }}{ }^{\circ} \mathrm{C}\right)}^{a}$} & \multirow[b]{2}{*}{$\begin{array}{l}T_{\mathrm{rl}}^{b} \\
\left({ }^{\circ} \mathrm{C}\right)\end{array}$} & \multirow[b]{2}{*}{$\begin{array}{l}T_{\mathrm{r} 2}^{b} \\
\left({ }^{\circ} \mathrm{C}\right)\end{array}$} & \multicolumn{3}{|c|}{ cycle 1} & \multicolumn{3}{|c|}{ cycle 2} & \multicolumn{3}{|c|}{ cycle 3} \\
\hline & & & & & $\begin{array}{c}R_{\mathrm{f}} \\
(\%)\end{array}$ & $\begin{array}{c}R_{\mathrm{r}(\mathrm{C}-\mathrm{B})} \\
(\%)\end{array}$ & $\operatorname{R}_{(\mathrm{r}(\mathrm{B}-\mathrm{A})}$ & $\begin{array}{c}R_{\mathrm{f}} \\
(\%)\end{array}$ & $\begin{array}{c}R_{\mathrm{r}(\mathrm{C}-\mathrm{B})} \\
(\%)\end{array}$ & $\begin{array}{c}R_{\mathrm{r}(\mathrm{B}-\mathrm{A})} \\
(\%)\end{array}$ & $\begin{array}{l}R_{\mathrm{f}} \\
(\%)\end{array}$ & $\begin{array}{c}R_{\mathrm{r}(\mathrm{C}-\mathrm{B})} \\
(\%)\end{array}$ & $\begin{array}{c}R_{\mathrm{r}(\mathrm{B}-\mathrm{A})} \\
(\%)\end{array}$ \\
\hline PE-3K & 315 & 200 & 137 & 289 & 91 & 67 & 60 & 93 & 80 & 66 & 89 & 79 & 73 \\
\hline PE-1K & 275 & 150 & 144 & 240 & 97 & 128 & 49 & 97 & 135 & 44 & 93 & 139 & 40 \\
\hline TPE-5 & 315 & 200 & 132 & 285 & 88 & 64 & 69 & 86 & 74 & 79 & 86 & 79 & 79 \\
\hline TPE-10 & 295 & 175 & 138 & 250 & 92 & 79 & 91 & 92 & 89 & 80 & 91 & 91 & 82 \\
\hline TPE-15 & 275 & 150 & 133 & 236 & 93 & 97 & 84 & 92 & 123 & 55 & 93 & 136 & 45 \\
\hline
\end{tabular}

${ }^{a} T_{\text {prog1 }}$ and $T_{\text {prog2 }}$ refer to the first and second programming temperature, respectively. ${ }^{b} T_{\mathrm{r} 1}$ and $T_{\mathrm{r} 2}$ refer to the temperature at the first and second maximum recovery velocity, respectively.
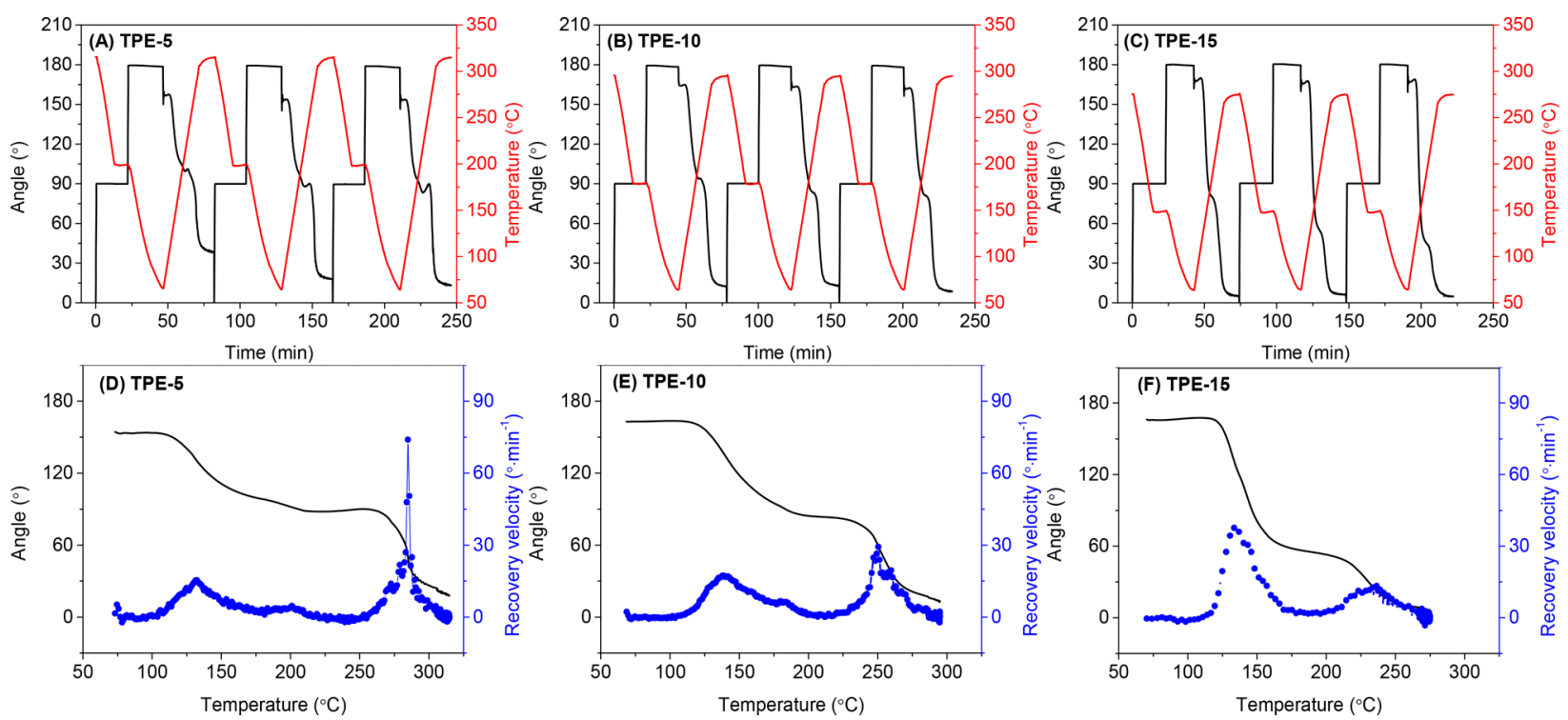

Figure 8. Three consecutive triple-shape memory cycles for (A) TPE-5, (B) TPE-10, and (C) TPE-15. Angular velocity of shape recovery as a function of temperature in the second cycle for (D) TPE-5, (E) TPE-10, and (F) TPE-15. Cooling and heating rate $10^{\circ} \mathrm{C}$ min ${ }^{-1}$ and $\mathrm{N}_{2}$ atmosphere.

leading to the final fixed temporary shape $\left(\varphi_{\mathrm{f}}\right)$. A shape fixation rate $\left(R_{\mathrm{f}}\right)$ of $\sim 90 \%$ was calculated using eq 4 .

$$
R_{\mathrm{f}}=\frac{\varphi_{\mathrm{f}}}{\varphi_{\mathrm{C}}} \times 100 \%
$$

In the subsequent recovery step, the sample was heated up to $315{ }^{\circ} \mathrm{C}$ in a stress-free state to monitor the recovery of the rotational angle. The shape recovery was accomplished in two distinct steps, as shown in Figure 7A. This means the thermoset can memorize two temporary shapes in one single shape memory cycle. The shape recovery rate $R_{\mathrm{r}(\mathrm{C} \rightarrow \mathrm{B})}$ and $R_{\mathrm{r}(\mathrm{B} \rightarrow \mathrm{A})}$ were calculated based on eqs 5 and 6 , respectively. ${ }^{21}$

$$
\begin{aligned}
& R_{\mathrm{r}(\mathrm{C} \rightarrow \mathrm{B})}=\frac{\varphi_{\mathrm{f}}-\varphi_{\mathrm{B} / \mathrm{rec}}}{\varphi_{\mathrm{C}}-\varphi_{\mathrm{B}}} \times 100 \% \\
& R_{\mathrm{r}(\mathrm{B} \rightarrow \mathrm{A})}=\frac{\varphi_{\mathrm{B} / \mathrm{rec}}-\varphi_{\mathrm{A} / \mathrm{rec}}}{\varphi_{\mathrm{B}}-\varphi_{\mathrm{A}}} \times 100 \%
\end{aligned}
$$

where $\varphi_{\mathrm{A}}, \varphi_{\mathrm{B}}$, and $\varphi_{\mathrm{C}}$ denote the rotational angle of shape $\mathrm{A}$ $\left(\varphi_{\mathrm{A}}=0^{\circ}\right)$, shape B $\left(\varphi_{\mathrm{B}}=90^{\circ}\right)$, and shape $\mathrm{C}\left(\varphi_{\mathrm{C}}=180^{\circ}\right) ; \varphi_{\mathrm{B} / \mathrm{rec}}$ and $\varphi_{\mathrm{A} / \mathrm{rec}}$ are the rotational angles of the first and second recovered shapes, respectively. Figure $7 \mathrm{~B}$ shows the triple-shape memory cycles of PE- $1 \mathrm{~K}$. This polymer exhibits a lower $T_{\mathrm{m}}$ $\left(244{ }^{\circ} \mathrm{C}\right)$ compared to $\mathrm{PE}-3 \mathrm{~K}\left(283{ }^{\circ} \mathrm{C}\right)$; therefore, lower programming temperatures $\left(275\right.$ and $150{ }^{\circ} \mathrm{C}$ ) were used.
PE-3K shows moderate $R_{\mathrm{r}(\mathrm{C} \rightarrow \mathrm{B})}$ values of $67-80 \%$ in the first recovery step and $R_{\mathrm{r}(\mathrm{B} \rightarrow \mathrm{A})}$ values of $60-73 \%$ in the second recovery step, as listed in Table 4. Compared to PE-3K, PE-1K shows much higher $R_{\mathrm{r}(\mathrm{C} \rightarrow \mathrm{B})}$ values of $128-138 \%$ and lower $R_{\mathrm{r}(\mathrm{B} \rightarrow \mathrm{A})}$ values of $40-49 \%$. The first recovery is triggered by the glass transition and is due to the release of stress in the amorphous phase. The major recovery takes place in the first step, indicating that the crystalline phase cannot completely lock the stress in the amorphous phase. The stress, which is supposed to release in the second recovery step, is actually partially released in the first recovery step. This, together with the stress induced by the second deformation, drives the sample to reach a high recovery rate $(>100 \%)$ in the first step. This result is consistent with the result we obtained from the dualshape memory experiments and originates from the low degree of crystallinity of the PE- $1 \mathrm{~K}$ thermoset.

Figures $7 \mathrm{C}$ and $7 \mathrm{D}$ show the shape recovery velocity of PE$3 \mathrm{~K}$ and PE- $1 \mathrm{~K}$ samples as a function of temperature. The first recovery step of PE-3K shows a lower $V_{\mathrm{r}}\left(13^{\circ} \mathrm{min}^{-1}\right)$ than the second step $\left(28^{\circ} \mathrm{min}^{-1}\right)$ because of the limited mobility of the amorphous chain segments restricted by the crystalline domains. In contrast, the PE- $1 \mathrm{~K}$ sample shows much higher $V_{\mathrm{r}}\left(54^{\circ} \mathrm{min}^{-1}\right)$ in the first step, which is due to its low degree of crystallinity.

The triple-shape memory cycles and recovery velocity of the TPE thermosets are shown in Figure 8. The TPE-5 and TPE-10 

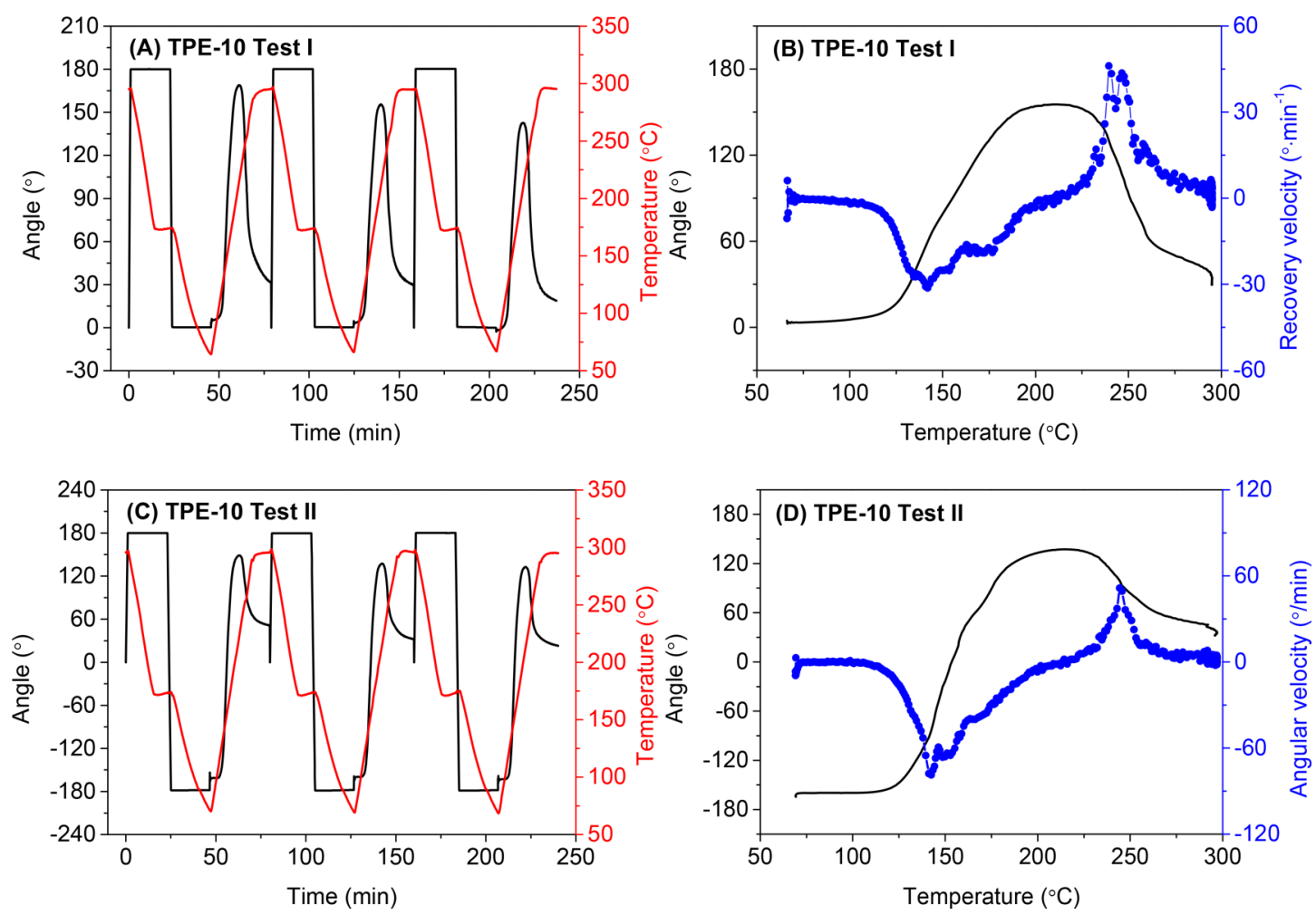

Figure 9. Three consecutive triple-shape memory cycles for TPE-10 and shape recovery velocity as a function of temperature in the second cycle. (A) and (B) deformation of $180^{\circ}$ and $-180^{\circ}$ in two steps, respectively; (C) and (D) deformation of $180^{\circ}$ and $-360^{\circ}$ in two steps, respectively.

films show moderate $R_{\mathrm{r}(\mathrm{C} \rightarrow \mathrm{B})}$ and $R_{\mathrm{r}(\mathrm{B} \rightarrow \mathrm{A})}(64-91 \%)$ and higher $V_{\mathrm{r}}$ values in the second recovery step, which is similar to the behavior of PE-3K, whereas the TPE-15 sample, similar to PE$1 \mathrm{~K}$, exhibits high $R_{\mathrm{r}(\mathrm{C} \rightarrow \mathrm{B})}(97-136 \%)$ and $V_{\mathrm{r}}$ values $\left(38^{\circ}\right.$ $\left.\mathrm{min}^{-1}\right)$ in the first recovery step, because this polymer has the lowest degree of crystallinity.

The temperatures at the first maximum recovery velocity $\left(T_{\mathrm{r} 1}\right)$ of all samples are within a narrow range of $132-144^{\circ} \mathrm{C}$ because the $T_{\mathrm{g}}$ of all samples is around $125^{\circ} \mathrm{C}$. However, the temperatures of the second maximum recovery velocity $\left(T_{\mathrm{r} 2}\right)$, which depend on the $T_{\mathrm{m}}$ of the samples, display a broad variation between 236 and $289^{\circ} \mathrm{C}$. Therefore, the triple-shape memory behavior of the thermosets is highly tunable over a wide temperature regime.

Besides deforming the sample in one direction only, more interestingly, we can involve both forward and backward deformations in a triple-shape memory cycle; therefore, the corresponding temporary shapes would recover in a reverse direction. To demonstrate this, the TPE-10 thermoset sample, which shows a high $R_{\mathrm{f}}(>90 \%), R_{\mathrm{r}(\mathrm{C}-\mathrm{B})}(\sim 90 \%)$, and $R_{\mathrm{r}(\mathrm{B}-\mathrm{A})}$ $(\sim 80 \%)$, was selected as a representative example.

The results of test I are shown in Figure 9A,B. The sample was programmed forward and backward by $180^{\circ}$ in two steps and reached a final temporary shape, which is identical to the original shape. The subsequent heating resulted in an increase in angle in the first recovery step achieving a maximum recovery velocity at $142{ }^{\circ} \mathrm{C}$ and an $R_{\mathrm{r}(\mathrm{C}-\mathrm{B})}$ of $79-91 \%$ at 213 ${ }^{\circ} \mathrm{C}$. By increasing the temperature further, the sample recovered in the reverse direction reaching a maximum recovery velocity at $243{ }^{\circ} \mathrm{C}$ and an $R_{\mathrm{r}(\mathrm{B}-\mathrm{A})}$ of $81-87 \%$ (Table 5). These results demonstrate that our semicrystalline PA thermosets show oneway reversible shape memory behavior. The reversible shape changes in this experiment occurred without application of any
Table 5. Triple-Shape Fixation and Recovery Results of TPE-10 Deformed in Two Opposite Directions

\begin{tabular}{|c|c|c|c|c|c|c|c|}
\hline test & $\begin{array}{c}\text { cycle } \\
\text { no. }\end{array}$ & $\begin{array}{c}\Delta \varphi_{\mathrm{d1}}{ }^{a} \\
(\mathrm{deg})\end{array}$ & $\begin{array}{c}\Delta \varphi_{\mathrm{d} 2}{ }^{a} \\
(\mathrm{deg})\end{array}$ & $\begin{array}{l}R_{\mathrm{f}} \\
(\%)\end{array}$ & $\begin{array}{c}R_{\mathrm{r}(\mathrm{C}-\mathrm{B})} \\
(\%)\end{array}$ & $R_{\mathrm{r}(\mathrm{B}-\mathrm{A})}$ & $\begin{array}{l}T_{\max }{ }^{b} \\
\left({ }^{\circ} \mathrm{C}\right)\end{array}$ \\
\hline \multirow[t]{3}{*}{ I } & 1 & 180 & -180 & 97 & 91 & 81 & 213 \\
\hline & 2 & 180 & -180 & 98 & 85 & 81 & 211 \\
\hline & 3 & 180 & -180 & 99 & 79 & 87 & 209 \\
\hline \multirow[t]{3}{*}{ II } & 1 & 180 & -360 & 90 & 86 & 54 & 218 \\
\hline & 2 & 180 & -360 & 89 & 83 & 59 & 213 \\
\hline & 3 & 180 & -360 & 91 & 82 & 61 & 212 \\
\hline
\end{tabular}

${ }^{a} \Delta \varphi_{\mathrm{d} 1}$ and $\Delta \varphi_{\mathrm{d} 2}$ refer to the deformation angles in the first and second deformation steps. ${ }^{b} T_{\max }$ refers to the temperature at the maximum angle.

external force. The shape changes were driven by internal stress of the oppositely strained networks formed in the first and second programming steps.

We can adjust the second programming step from $\Delta \varphi_{\mathrm{d} 2}=$ $-180^{\circ}$ to $\Delta \varphi_{\mathrm{d} 2}=-360^{\circ}$ in test II, which results in two opposite temporary shapes, as shown in Figure 9C,D. The sample shows a $R_{\mathrm{f}}$ of $89-91 \%, R_{\mathrm{r}(\mathrm{C}-\mathrm{B})}$ of $82-86 \%$, and $R_{\mathrm{r}(\mathrm{B}-\mathrm{A})}$ of $54-61 \%$ (Table 5 ). The maximum recovery velocity occurs at 142 and $244{ }^{\circ} \mathrm{C}$ in the first and second recovery steps, respectively, which is consistent with the results of Test I. Our results clearly demonstrate that high-temperature SME with tunable recovery directions and amplitudes can be designed based on our single-component semicrystalline polyamide thermosets.

\section{CONCLUSIONS}

We have investigated two novel series semicrystalline PA thermosets and demonstrated that they can be as singlecomponent high-temperature $\left(>200{ }^{\circ} \mathrm{C}\right)$ shape memory 
polymers (SMPs). Two molecular design approaches based on reactive phenylethynyl (PE) functionalities have been explored: cross-linked semicrystalline PA films were prepared by curing reactive thermoplastic PA 10T oligomers, and films were prepared by curing reactive thermoplastic side-group functionalized copolyamides. Compared to the thermoplastic PA 10T reference polymer, the PE-3K, TPE-5, and TPE-10 thermoset films show high-temperature dual-shape memory behavior $\left(>200{ }^{\circ} \mathrm{C}\right.$ ) when $T_{\mathrm{m}}$ is used as the switching temperature. The densely cross-linked PE-1K and TPE-15 films show the highest fixation rate $(99 \%)$ and recovery rate $(\geq 90 \%)$ and two distinct recovery steps because the degree of crystallinity is too low and cannot provide a scaffold that locks the shape at temperatures between $T_{\mathrm{g}}$ and $T_{\mathrm{m}}$. Triple-shape memory behavior can be demonstrated when the $T_{\mathrm{g}}\left(\sim 125{ }^{\circ} \mathrm{C}\right)$ is used as the second switching temperature. The recovery rate of the two recovery steps is highly dependent on the degree of crystallinity of the thermosets and vary within a broad range of $74 \%-139 \%$ and $40-82 \%$ for the first and second step, respectively. One-way reversible shape memory events can also be designed when we perform forward and backward deformation in a triple shape memory cycle. We also studied the recovery velocity as a function of temperature to elaborate the thermokinematics of the shape recovery process. The use of phenylethynyl reactive functionalities allows us to control the degree of crystallinity in the final polyamide thermosets and in turn tune their shape memory behavior in terms of recovery temperature, velocity, and efficiency. We believe that the design rules presented herein will help in designing new shape memory polymers based on well-known semicrystalline polyamide chemistries.

\section{ASSOCIATED CONTENT}

\section{(5) Supporting Information}

The Supporting Information is available free of charge on the ACS Publications website at DOI: 10.1021/acsami.8b03658.

Figure S1 (PDF)

\section{AUTHOR INFORMATION}

\section{Corresponding Author}

*E-mail: tjd@unc.edu (T.J.D.).

\section{ORCID $\odot$}

Qingbao Guan: 0000-0002-3384-3229

Theo J. Dingemans: 0000-0002-8559-2783

\section{Present Address}

T.J.D.: Department of Applied Physical Sciences, University of North Carolina at Chapel Hill, 1113 Murray Hall, 121 South Road, Chapel Hill, NC 27599-3050.

\section{Notes}

The authors declare no competing financial interest.

\section{ACKNOWLEDGMENTS}

This research forms part of the research program of the Dutch Polymer Institute (DPI), Project \#743. The authors thank the DPI for financial support. The authors thank Prof. S. Sheiko, Dr. J. Bijleveld, Dr. R. Bose, and Dr. R. Rulkens for fruitful discussions.

\section{REFERENCES}

(1) Xie, T. Recent advances in polymer shape memory. Polymer 2011, 52 (22), 4985-5000.
(2) Hu, J.; Zhu, Y.; Huang, H.; Lu, J. Recent advances in shapememory polymers: Structure, mechanism, functionality, modeling and applications. Prog. Polym. Sci. 2012, 37 (12), 1720-1763.

(3) Rousseau, I. A. Challenges of shape memory polymers: A review of the progress toward overcoming SMP's limitations. Polym. Eng. Sci. 2008, 48 (11), 2075-2089.

(4) Behl, M.; Razzaq, M. Y.; Lendlein, A. Multifunctional ShapeMemory Polymers. Adv. Mater. 2010, 22 (31), 3388-3410.

(5) Pilate, F.; Toncheva, A.; Dubois, P.; Raquez, J.-M. Shape-memory polymers for multiple applications in the materials world. Eur. Polym. J. 2016, 80, 268-294.

(6) Hager, M. D.; Bode, S.; Weber, C.; Schubert, U. S. Shape memory polymers: Past, present and future developments. Prog. Polym. Sci. 2015, 49-50, 3-33.

(7) Leng, J.; Lan, X.; Liu, Y.; Du, S. Shape-memory polymers and their composites: stimulus methods and applications. Prog. Mater. Sci. 2011, 56 (7), 1077-1135.

(8) Zhao, Q.; Qi, H. J.; Xie, T. Recent progress in shape memory polymer: New behavior, enabling materials, and mechanistic understanding. Prog. Polym. Sci. 2015, 49-50, 79-120.

(9) Wu, X.; Huang, W. M.; Zhao, Y.; Ding, Z.; Tang, C.; Zhang, J. Mechanisms of the shape memory effect in polymeric materials. Polymers 2013, 5 (4), 1169-1202.

(10) Meng, H.; Li, G. A review of stimuli-responsive shape memory polymer composites. Polymer 2013, 54 (9), 2199-2221.

(11) Lewis, C. L.; Dell, E. M. A review of shape memory polymers bearing reversible binding groups. J. Polym. Sci., Part B: Polym. Phys. 2016, 54 (14), 1340-1364.

(12) Xiao, X.; Kong, D.; Qiu, X.; Zhang, W.; Liu, Y.; Zhang, S.; Zhang, F.; Hu, Y.; Leng, J. Shape memory polymers with high and low temperature resistant properties. Sci. Rep. 2015, 5, 14137.

(13) Xiao, X.; Kong, D.; Qiu, X.; Zhang, W.; Zhang, F.; Liu, L.; Liu, Y.; Zhang, S.; Hu, Y.; Leng, J. Shape-memory polymers with adjustable high glass transition temperatures. Macromolecules 2015, 48 (11), $3582-3589$.

(14) Shi, Y.; Weiss, R. Sulfonated Poly (ether ether ketone) Ionomers and Their High Temperature Shape Memory Behavior. Macromolecules 2014, 47 (5), 1732-1740.

(15) Shi, Y.; Yoonessi, M.; Weiss, R. High temperature shape memory polymers. Macromolecules 2013, 46 (10), 4160-4167.

(16) Yang, Z.; Chen, Y.; Wang, Q.; Wang, T. High performance multiple-shape memory behaviors of Poly (benzoxazole-co-imide) s. Polymer 2016, 88, 19-28.

(17) Xiao, X.; Qiu, X.; Kong, D.; Zhang, W.; Liu, Y.; Leng, J. Optically transparent high temperature shape memory polymers. Soft Matter 2016, 12 (11), 2894-2900.

(18) Bai, Y.; Mao, L.; Liu, Y. High temperature shape memory polyimide ionomer. J. Appl. Polym. Sci. 2016, 133 (30), 43630-43637.

(19) Wang, Q.; Bai, Y.; Chen, Y.; Ju, J.; Zheng, F.; Wang, T. High performance shape memory polyimides based on $\pi-\pi$ interactions. J. Mater. Chem. A 2015, 3 (1), 352-359.

(20) Koerner, H.; Strong, R. J.; Smith, M. L.; Wang, D. H.; Tan, L.S.; Lee, K. M.; White, T. J.; Vaia, R. A. Polymer design for high temperature shape memory: Low crosslink density polyimides. Polymer 2013, 54 (1), 391-402.

(21) Guan, Q.; Picken, S. J.; Sheiko, S. S.; Dingemans, T. J. HighTemperature Shape Memory Behavior of Novel All-Aromatic (AB)nMultiblock Copoly(ester imide)s. Macromolecules 2017, 50 (10), 3903-3910.

(22) Bellin, I.; Kelch, S.; Langer, R.; Lendlein, A. Polymeric tripleshape materials. Proc. Natl. Acad. Sci. U. S. A. 2006, 103 (48), 1804318047.

(23) Behl, M.; Lendlein, A. Triple-shape polymers. J. Mater. Chem. 2010, 20 (17), 3335-3345.

(24) Xie, T.; Xiao, X.; Cheng, Y. T. Revealing triple-shape memory effect by polymer bilayers. Macromol. Rapid Commun. 2009, 30 (21), 1823-1827.

(25) Xie, T. Tunable polymer multi-shape memory effect. Nature 2010, 464 (7286), 267-270. 
(26) Li, M.; Dingemans, T. J. Synthesis and characterization of semicrystalline poly (decamethylene terephthalamide) thermosets. Polymer 2017, 108, 372-382.

(27) Li, M.; Bijleveld, J.; Dingemans, T. J. Synthesis and Properties of Semi-crystalline Poly(decamethylene terephthalamide) Thermosets from Reactive Side-group Copolyamides. Eur. Polym. J. 2018, 98, $273-284$.

(28) Wagermaier, W.; Kratz, K.; Heuchel, M.; Lendlein, A. Characterization methods for shape-memory polymers. In ShapeMemory Polymers; Springer: 2009; pp 97-145.

(29) Diani, J.; Fredy, C.; Gilormini, P.; Merckel, Y.; Régnier, G.; Rousseau, I. A torsion test for the study of the large deformation recovery of shape memory polymers. Polym. Test. 2011, 30 (3), 335341.

(30) Baghani, M. Analytical study on torsion of shape-memorypolymer prismatic bars with rectangular cross-sections. Int. J. Eng. Sci. 2014, 76, 1-11.

(31) Baghani, M.; Naghdabadi, R; Arghavani, J.; Sohrabpour, S. A constitutive model for shape memory polymers with application to torsion of prismatic bars. J. Intell. Mater. Syst. Struct. 2012, 23 (2), 107-116.

(32) Diani, J.; Gilormini, P.; Frédy, C.; Rousseau, I. Predicting thermal shape memory of crosslinked polymer networks from linear viscoelasticity. Int. J. Solids Struct. 2012, 49 (5), 793-799.

(33) Roberts, C. C.; Apple, T. M.; Wnek, G. E. Curing chemistry of phenylethynyl-terminated imide oligomers: Synthesis of 13C-labeled oligomers and solid-state NMR studies. J. Polym. Sci., Part A: Polym. Chem. 2000, 38 (19), 3486-3497.

(34) Iqbal, M.; Norder, B.; Mendes, E.; Dingemans, T. J. All-aromatic liquid crystalline thermosets with high glass transition temperatures. J. Polym. Sci., Part A: Polym. Chem. 2009, 47 (5), 1368-1380.

(35) Lendlein, A.; Kelch, S. Shape-memory polymers. Angew. Chem., Int. Ed. 2002, 41 (12), 2034-2057.

(36) Véchambre, C.; Buléon, A.; Chaunier, L.; Gauthier, C.; Lourdin, D. Understanding the mechanisms involved in shape memory starch: macromolecular orientation, stress recovery and molecular mobility. Macromolecules 2011, 44 (23), 9384-9389. 